\title{
RESHAPING THE LANDSCAPE OF CARE: HEALTH APPS AND THE ETHICS OF SELF-RESPONSIBILITY AND CARE FOR THE OTHER
}

\author{
Susanna Trnka ${ }^{1} \&$ Andrea Merino Ortiz
}

\begin{abstract}
This article considers the ethical implications of health apps, focusing on how digital technologies create new temporalities of care for the self and for others. Drawing on our own experiences of engaging in digital care, we examine how apps that focus on mood/emotion tracking, mental health, meditation, and other forms of stress-relief reconfigure inter-relationality. Recasting how information is shared as well as the temporal possibilities of social exchanges, such health apps enable 'friends' we know or are coming to know, as well as those we do not want to know, to enter into some of the most intimate aspects of our lives, as they unfold in the open-ended flow of time. In doing so, health apps, we suggest, demand a rethinking of the ethics of how we constitute and care for both the self and a variety of (known and unknown) others.
\end{abstract}

Keywords: health apps; care; ethics; sociality; temporality

\section{INTRODUCTION}

'Andrea, how is your mood today?'

I stare at the screen of my iPhone 4 , after a notification summons me to check my mobile. My mood tracker wants to know how I am feeling today. Well, Moodtrack Diary, to be honest - I am not sure. I was not really thinking about it until now...

I have only been trying out health apps for about a couple of weeks, and this message is already one of the many daily reminders I get regarding my well-being. My Stop, Breath and Think App keeps sending me messages such as: 'Feel the Calm in 5 Minutes. Easy!' 
or 'Haven't meditated in a while? There is no time like the present to check in and feel the calm', while my Optimism App gives me 'Stay Well Strategies' and ways of coping with my 'Anxiety Triggers'. I feel like I have a whole football team behind me, cheering me on twenty-four hours a day, especially as I get some of these messages at three o'clock in the morning. I guess I need to 'check in' with my mind even when I am dreaming... (Merino Ortiz)

In this article we examine how health apps create new temporalities of care for the self and others, reconstructing the landscape of care so that health and mood maintenance can become an all-day - and sometimes all-night - enterprise. We consider how these emerging technologies reconfigure interrelationality, expanding virtual communities of care by making individual and collective efforts towards getting and staying well available almost anywhere, anytime, and, in the process, interweaving digital care-giving into the flow of daily life. Throughout, our attention focuses on the ethical considerations that such forms of intensified communication elicit, in particular our moral obligations to ourselves and to others.

Our reflections stem out of six months spent experimenting with various health apps. We did not try to sample them all; by one account, there were approximately 165,000 mobile health apps on the market as of September 2015 (Riaz 2015). Rather, given our specific interest in mental health, we predominantly selected apps focused on mental wellbeing. One of us (Trnka) focused on interactive mental health, relationship, and addiction apps, while the other (Merino Ortiz) tried out a range of diaphragmatic breathing programmes, stress-relief and meditation apps, and mood/emotion trackers. We both also gave period trackers (which also act as predictors of premenstrual syndrome (PMS) and fertility trackers) a brief try. The technologies we tried out offer a range of services from self-diagnoses and general stress-relief tips, to personalised self-care programmes and comparisons of one's biodata with that of users from around the world. In addition to our own forays into the world of digital healthcare, we expanded our understandings of what it is like to use these technologies through exchanging stories with our colleagues and students, as well as conducting formal interviews with young New Zealanders about their experiences with digital healthcare (see Trnka 2016). These interchanges suggested that the category of 'health apps' as used by New Zealanders is extremely wide ranging, including anything from apps that communicate emotional expression ('Vent', for example) to apps that track data about specific conditions or those designed to enhance fitness and nutrition. 
Much of the current discussion about the ethics of health apps is devoted to analysing how these technologies amass commercially valuable information, turning users' self-tracking into profit-generating enterprises (e.g. Bujink et al. 2012; Lupton 2014a). Our focus in this article is on another facet of health apps, namely the variety of personal and inter-personal relations - and ethical issues - that their use can generate.

A growing body of research has examined various aspects of 'life online', ranging from how health information is constituted through online interactions (Broom 2005; Wynn et al. 2010) and the power dynamics that underpin support groups (Brotsky and Giles 2007; Preece 1999), to how romance and sexuality are enacted on the internet (Bardzell and Bardzell 2006; Boellstorff 2015). Within the literature on eHealth, as well as in studies of contemporary health more broadly, much has been made of how online technologies reconfigure one's relationship to the self, inculcating a new ethic of self-responsibility and effectively 'responsibilising' us into so-called 'expert patients' who self-manage our own health and well-being (Rose 2006; see also Dumit 2012; Lewis 2006; and Lupton 2013, 2014b). Following Nikolas Rose (2006), 'responsibilisation' refers to how advanced liberal reforms both enable and require people to take on greater personal autonomy, self-responsibility, and self-reliance. Frequently undertaken the banner of increasing individual 'choice', increasing patient's own responsibility for their healthcare is often part of large-scale moves to devolve a range of social services from the state onto individuals (Rose 2006, 1990). While it can indeed in some cases lead to a greater sense of independence and competence, the emphasis on self-responsibility can also result in patients feeling overwhelmed, and being both under resourced and not adequately educated to make potentially life-altering decisions about their health - in other words, in need of being cared for, rather than caring for themselves (Trnka 2017).

There is a decidedly moral edge to this understanding of the self, as those who are unable - or unwilling - to self-manage are deemed to be morally deficient (Rose 2006). They are, moreover, seen as guilty of letting down not only themselves but society as a whole; as Michel Foucault (1997 [1994]) long ago noted, the 'care for the self' is intimately imbricated with the goals of liberal government. The imperative to create oneself, and continually keep re-creating oneself, is, as Giddens (1991) and other scholars (e.g. Tanner, Maher, and Fraser 2013) have noted, part of contemporary identity. Technology has become increasingly central to this project, in terms of both constituting and managing the self (Downey and Dumit 1997; Dumit 2012). 
Inspired by Deborah Lupton's work (e.g. 2012, 2013, 2014a, 2014b) on how apps are shaping our understandings of personhood, risk, and responsibilisation, in this essay, we address the question of self-management within a larger exploration of the sociality of care. Taking issue with how online relations have often been characterised as 'fleeting' (or, in Bauman's (2003) terms, 'liquid'), we take seriously the ethical obligations users of health apps may feel not only to themselves as the subject of care, but to others who interact with them online. While our experiences with health apps underscore the emphasis contemporary healthcare practices place on self-management and patient expertise, we were surprised to discover the levels of social engagement that many health apps entail. Indeed, users' activities often reflect the notion that while each individual should be vested with primary responsibility for his or her own health and wellbeing, another aspect of enacting self-care is to check and cross-check the significance and purported 'normalcy' of a variety of facets of one's emotional and physical states of being with others. The nearly instantaneous nature of interactions enabled by mobile technologies intensifies the possibilities of enacting collective care; extending the scope of those who might be involved in tracking and shaping our behaviours. It reconfigures health as a particular kind of personal and collective enterprise.

The potential, however, for nearly instantaneous inter-relationality with members of various shifting communities of virtual 'friends' (who are, in other respects, usually strangers to us) does not come without ethical entanglements. Being able to communicate about one's wellbeing at the touch of a button - and sometimes, as we found out, communicating information about oneself without even intending to - creates new demands as well as different forms of expectation, anticipation, and obligation to others. As with most forms of cosmopolitanism (George, Fitzgerald, and Jaye 2016), in the cosmopolitan terrain of cyberspace, there are guiding principles for managing relationships; here, however, the principles of how to (best) engage in new forms of collective care are still being developed.

In asking how health apps recast the temporality of social exchange, opening up new ethical questions about obligations to the self and to others, our conceptualisation of ethics focuses on everyday acts of inter-personal communication. As opposed to the findings of formal bioethical deliberations, we are interested in how ethical decision-making takes place as part of the ebb and flow of everyday life - processes which Paul Brodwin (2013) has referred to as 'everyday ethics', or, in Michael Lambek's (2010) terms, the 'ordinary ethics' created through language and action in the course of everyday life. We thus take the moral dimensions of health apps very seriously, but engage with them as, 
following Fassin's approach to morality $(2012,3)$, 'objects of study', underscoring where and how we see moral tensions at play, rather than attempting to come up with our own, definitive moral judgements.

\section{TRACKING DEVICES}

We started off by exploring a group of health apps that initially appeared to be little more than electronic versions of traditional documentation devices. What could we achieve, we wondered, using a fitness, nutrition, or menstrual cycle app to record our data that a simple calendar and spreadsheet could not provide? We soon realised that tracking apps do a lot more than merely track one's information. In building associations between different elements of biodata, they set up a framing of the future that anticipates and indeed prompts particular patterns and forms of behaviour.

Period trackers, for example, do much more than track and forecast the dates of one's menses and fertility cycles. 'Clue' is a popular period tracker among young women, largely due the discretion of both its name and icon (as opposed to apps such as 'Period Tracker Lite' or 'Monthly Cycles', both of which feature bright pink icons and leave little to the imagination should someone else get a hold of your phone). In addition to its calendar feature which leaves you in no suspense about when your next period is due, Clue quizzes users about a wide range of menstrual-related and, one could argue, non-menstrually related physical and emotional phenomena and activities. Users are encouraged to enter daily data documenting over 150 possible conditions and activities, including their:

- level of bleeding ('light', 'medium,' 'heavy' or 'spotting');

- emotions ('happy,', 'sensitive,'sad', or the rather unclear, catch-all category of 'PMs');

- hours of sleep the previous night;

- sexual activity ('unprotected', 'protected', 'high sex drive', or 'withdrawal');

- food cravings;

- quality of digestion;

- good or bad hair day (with options for 'oily' or 'dry');

- motivation levels;

- appointment (defined as 'ob/gyn', 'vacation', 'doctor', or 'date');

- party activities ('drinks,' 'cigarettes', 'hangover', or 'big night');

- and stool quality;

- plus their own personalised categories, which users can add in to the database. 
On the basis of the daily input of such data, the app provides an 'analysis' section that paints a complicated portrait of what a user's month might look like. Complete with a calendar that visually marks one's upcoming emotions and other possible symptoms - with, for example, grey clouds looming on the days of expected PMS - the app not only prepares users for coping with PMS symptoms that might be just around the corner, but fosters a sense of anticipation and expectation of them.

Another period tracker we tried took this a step further, sending us notifications based on where we were in our cycles, with purportedly helpful hints such as 'Day 18: Progesterone is on the rise today. It's a hormone that inspires nurturing and nesting, so don't be surprised if you find yourself cleaning up or organising the home, baking muffins or re-decorating your home. On another day it notified us that at this point in a woman's cycle, 'you are feeling sexy and extremely turned on...' In this case, it was not our own norms, but very dubious expectations of how women should and will behave at certain points in their monthly cycles, that became part and parcel of 'tracking' our cycles. There was in fact no way for us to ascertain where this information had come from. As yet, there is no regulation of health apps, which means that developers can create tools for self-diagnosis or the promotion of health and wellness advice without any medical input or oversight (Bujink et al. 2012; Lupton 2014a). Nor do they need to document the sources of the medical advice their devices communicate.

The anticipatory outlooks embodied in such tracking programmes are the hallmark of contemporary approaches to healthcare (Adams et al. 2009). Health apps, however, bring the predictive mode of self-managed care into a new dimension as many of the expected symptoms and bodily states they foretell are ostensibly derived from patterns based on data that is specific to one's own body. Clue's forecasts appear objective, as if the app is merely reflecting the information the user supplied to it. The app reinforces the notion that we each follow our own self-created 'norms', now made crystal clear through the tracker's 'analysis'. And yet the very idea that moods and sensations will be replicable from one cycle to another is itself questionable. So too is the purported cause-and-effect relationship between menstrual cycles and the huge range of mental and physical states of being that Clue encourages us to enter into the database. While we are not claiming that there is never a cause-and-effect relationship between menstrual cycles and some of the conditions listed, to enter in a month or two of one's 'data' and expect the 'results' to be anything but correlations, and sketchy ones at that, is misleading. 
Both of us found the technology more disconcerting than useful. Rather than encouraging us to pay more heed to our bodies, we felt alienated by the intrusion of a third party into what feel like very intimate bodily processes. Merino Ortiz felt uncomfortable with the amount of personal, intimate data that the period app makers were collecting about her. This was not helped when we went on the 'Clue' website and read the biographical profiles of Clue's Berlinbased employees, complete with their photos and images of their 'favorite' Clue icons (such as the bunny rabbit for 'high sex drive.)

Trnka was more annoyed by the communications she received from the various apps. When faced with grey clouds on the calendar foretelling a bad week ahead, Trnka reflected:

The possibility of anomalies or ruptures, of the unexpected that is so often a part of bodily experience, feels foreclosed, as not only my supposed 'symptoms' but my moods and energy levels (and even sexual desires!) are purportedly able to be mapped out in advance. In trying to tell me too much about what is coming up, the app threatens to either create specific kinds of futures via anticipation, or completely alienate me from its purpose.

And yet, we both also found it hard to get away from the allure that all of this information - generated by me, about me - might be able to offer a privileged outlook on our futures. Getting the period trackers' messages on our own phones, nestled alongside emails and texts from friends and family, only made the information appear seductively selective, private and somehow intimately linked to $u s$. The desire to know oneself, in order to better be able to extend care to the self and take charge of our own health and wellbeing, made it hard - but also even more imperative - to remember that despite Clue's slick design and easy accessibility, the app might not have a clue about the kinds of futures it was setting up for us.

\section{REALIGNING BODY AND BREATH}

While we had not expected the possibility of period trackers actively attempting to re-shape our moods or behaviours, other apps are explicitly designed as tools for changing one's activities in order to achieve better health and wellbeing. Out of the very broad range of health, fitness, and nutrition apps that are available today, we chose to focus on breathing and meditation apps intended to mitigate stress. 
There are a number of apps designed to counteract panic attacks and calm hyperventilation that work by detecting users' breathing patterns and guiding them to change their breathing patterns. Merino Ortiz gave one of these apps a try, and while it initially had the effect of disrupting her ability to relax, she soon learned how to use the tool effectively:

At the start of the programme, I was instructed to use sound-proof headphones, as this would make the exercise more effective. Another pop-up message instructed me to lie down, place my phone on my belly and try to 'breathe normally'. The next message indicated I had to try to breathe into my belly very slowly and deeply; filling it with air so the phone rose and fell with my breath. Lastly, I was told to synchronise my breathing to the sound of the waves that would start playing any moment after a few of these breaths. As the sound of the waves began, I noticed myself naturally wanting to follow their rhythm, and after a few minutes I reached a point where I could no longer tell whether it was the waves directing my breath, or my belly's rise and fall orchestrating the musical arrangement. All of a sudden - and it felt a bit as if the app had read my mind - the sound of the waves swiftly switched to acoustic orchestral music, which sounded like it was arranged to coincide with the movement of my belly.

I began to feel very light, as if I was floating. Waves of sound hovered from my belly to my head and down to my legs and arms; with every breath, different pitches of sound created different muscular responses. I began noticing my back and legs relaxing, and I became increasingly able to expand my belly and hold in the air for longer and longer periods of time. I started to feel drowsy and sleepy from all the over-oxygenation, like someone had knocked me out with a blissful blow. But as soon as I had this thought, my breathing shifted and all of a sudden, the music abruptly stopped and the app sent another pop-up message, this one warning me: 'abnormal breathing detected'. I found myself forcing my breath into my belly again, craving that feeling of relaxation and the sound that I had now become accustomed to. Alas, by trying to anxiously force my breathing to slow down, I began yawning uncontrollably. This set the app off again and a renewed round of messages warned, 'abnormal breathing detected'. After about an hour of receiving warning messages in what felt like twenty second intervals, I had to stop the exercise, feeling less relaxed than I had before starting it. 
It took a few more tries before I learned how to use the app without triggering warnings of 'abnormal breathing.' But three months onward, if I'm ever having trouble getting to sleep, I turn on the app and after about ten minutes of diaphragmatic breathing to the sound of waves and orchestral music, I'm in a deep slumber.

In this case, we found that by altering our bodies (i.e. our breathing) in the ways demanded by the app, we achieved the desired outcome. Despite feeling initially disempowered, the overall effect was to leave us feeling more in control of our abilities to relax, bringing our focus of attention onto the body and the self. This was, however, an awareness mediated through technology, which made our sense of agency feel partial at best: being in control of technology which appears to control our actions, in the sense of setting the pace of our breathing, created a sense of agency as co-constituted and thus also dependent upon the apparatus.

With this experience behind us, we turned an eager eye towards a range of meditation apps, only to find yet another new facet of stress-relief we had not anticipated: competition.

\section{QUANTIFYING AND COMPARING WELLNESS}

A range of meditation apps is available, some of which are overtly religious while others are more spiritual, offering users a route to finding 'inner peace' as they connect with 'nature' through meditations that include background sounds of waterfalls and gentle breezes, while their phone's screensaver turns into a moving picture of passing clouds or mountains. Almost all of these apps are ostensibly focused on health, with an introductory section that explains the benefits of meditation, frequently drawing on an array of quotes from certified physicians.

Surprisingly, all of the apps we tried out required users to quantify their meditation through diaries, charts and graphs that track how long your meditation was, how successful it felt, and how relaxed you were afterwards. Unless otherwise specified by users, this information is uploaded and shared with other users, so they can track and compare their progress against yours.

Merino Ortiz, who had devoted three years to practicing meditation before trialing these apps, found the results alarming:

According to my meditation stats, I am a failure - I do not meditate 
long enough, or change my mood significantly through meditation. Actually, I cannot really tell how long (or how 'well') I meditate, as my logs are inconsistent and sporadic. I would have to be extremely disciplined if I wanted to produce more realistic charts and graphs. But what about other users? Are their logs equally flawed or are they the disciplined ones while I just lack the necessary willpower? Then there is the fact that the Stop, Breathe and Think app has me start every session by 'checking in with myself' by selecting from a range of 'smiley' to 'sad' face icons, just to do it again at the end of the meditation. This makes me more confused as most of the time the five choices presented by various icons are not enough to describe how I am feeling. Even more frustrating is how this app has a 'My Progress' tab in which I never 'Earn a Sticker' for improving my meditations. What am I doing wrong?

For Merino Ortiz, the tension between being reminded to 'check in with yourself' and 'check in with the rest of the world', raised unsettling questions of whether meditation, which she had always understood to be an internal exercise, can be carried out in competition? On the one hand, she found these apps helpful for keeping track of how her meditations were going, and effectively encouraging her to avoid becoming complacent and to apply more effort in developing and improving her awareness of her meditation practice. Like the mood trackers, however, sometimes these demands for reflection felt like too much, and resulted in wanting to discontinue what initially felt like a positive endeavor. She also found the apps encouraged her to become self-conscious about her results, even at times, tempting her to tweak her stats a little so that others would think she was doing better. At some points in the process, she felt inclined to quit the app altogether in order to escape the fact that she felt so 'behind' in her progress.

In this case, rather than being a technology that enables 'responsibilisation', this app incited a desire to care for the self by removing oneself from the pressures of inter-personal competition. In doing so, Merino Ortiz refused the apps' silent translation of meditation into a quantifiable and potentially agonistic practice, asserting her own definition of what meditation is intended to be against the hidden assumptions that govern meditation as a technologicallymediated practice.

MAKING AND BREAKING CONNECTIONS IN REAL-TIME

While meditation apps encouraged comparison and competition, other apps 
are specifically intended to create 'support' networks, ostensibly bringing together users to share and exchange their experiences. A central focus of mood or emotion trackers and other mental health apps is on creating communities of care. These virtual communities of care are often the same communities created on online support fora, but with the benefit of being accessible via health apps on mobile phones, making them potentially available anytime, anywhere, [for] anyone' (De Vries 2012, 12).

The potential for social alienation through online exchanges has been widely noted by scholars. In her ground-breaking work on the social effects of online technologies, Sherry Turkle (2011) argues that in looking for more connection, users of online technologies end up increasingly isolated from intimate relations. Zygmunt Bauman has similarly characterised online communities as fostering 'liquid' relations with 'connections [...] too shallow and brief to condense into bonds. Focused on the business in hand, they are protected against spilling over and engaging the partners beyond the time and the topic of the message dialled and read. [...] Virtual proximity can be, both substantively and metaphorically, finished with nothing more than the press of a button' $(2003,62)$.

A different perspective, however, emerges from the work of anthropologists, sociologists, and health researchers who have spent significant amounts of time within online communities. Taking part in online fora ranging from Second Life to pro-anorexia groups, these researchers suggest that some (but certainly not all) users go to great lengths to create sustained interactions, some of which do indeed 'spill over' and move 'beyond the time and the topic of the message' under discussion (Boellstorff 2015; Brotsky and Giles 2007).

Our experiences uphold the latter perspective, with the added caveat of revealing how the mobile nature of virtual communities of care constituted through health apps can heighten a sense of real-time engagement, leading to not only sustained connection, but also, at times, a sense of collective or inter-personal obligation between users. Trnka spent six months studying various downloadable mental health apps, focusing on virtual communities of care devoted to coping with relationship issues, alcoholism, and depression and anxiety. She found that not only do many users express extremely strong feelings about the role these fora play in their self-care, but a significant number appear to go to great lengths to use them to create sustained inter-personal connections, some of which endure long past the press of an 'off' button. And in many instances, there is no 'off' button available, as users are continuously messaged, and thus engaged, through apps that run on their phones twenty-four hours a 
day, almost anywhere they might be. Turkle $(2008,122)$ has spoken of this in terms of how the internet creates 'tethered selves', bound through technology to simultaneously engage with the physically real and lives onscreen.

Not surprisingly, most exchanges in these fora are focused on creating supportive and empathetic environments, though what exactly is meant by 'support' can sometimes be a point of contention among users (cf. Brotsky and Giles 2007). Users frequently reflect on the importance of both the content of the advice and support they receive as well as its immediacy. Frequently referring to themselves as members of the same 'community', it is not unusual for posters to note 'I love you [Website Name]!' or to post that they 'couldn't do it without this community.' In open-ended weekly 'shares', users are encouraged to post their stories, sometimes listing their real first names, cities of residence and revealing details such as ages and occupations. Posters also often make in-jokes or refer to privileged knowledge to mark their long-standing acquaintance with one another - 'how's the weather in Chicago today?' or 'how was your run this morning?' they might write, in response to a thread focused on replacing one's regular choice of beer and wine with seltzer water. Not infrequently, users lament the absence of old 'friends' when a particular regular seems to have fallen out of sight for a number of weeks.

There are also moments when users make a point of explicitly highlighting their desire for sustained engagement, often in response to someone who describes themselves as being in a particularly dire situation. Suicide threats, for example, frequently elicit messages promising ongoing support, along with the listing of various national suicide hotline numbers. 'Does anyone know what happened to [username] who was posting here last night?' someone wrote the day after another poster had been writing about considering suicide. On other occasions, expressions of the ongoing nature of posters' concerns for one another occur in response to more innocuous events: 'I remember you well, and have been reading your posts since you first came on here', posted one user to another on a mental health site. 'I'm taking a special interest in your situation, wrote a long-time member to a newcomer on an anti-anxiety site. There are also moments when these engagements translate into off line encounters. Some fora for example hold offline meet and greet sessions, inviting users to join them for dinner at a particular restaurant on a specific day.

While much of this behaviour is an extension of the kinds of sociality that have occurred for decades on online fora, the ability to interact with virtual communities of care through apps casts open the temporal dimensions of these interchanges. Simply put, users no longer need to wait for desktops or laptops 
to be available to communicate. Rather, the mobility enabled by health apps means that they can seek advice in real-time, as situations unfold, for example, posting from their car as they sit in the car park trying to muster up the courage to attend an AA meeting, or posting an update on how the meeting is going during a coffee break. Other users can respond with advice and encouragement, knowing that their words will have an impact as the event unfolds. It also means that health advice and support can seep into almost any part of users' days, with some posting that they are overseas on a work trip or holiday, lying by the swimming pool but nonetheless seeking to 'check in' and stay on track with their health or recovery programme.

Some users also express having a unique and privileged sense of control over the timing of their interactions, choosing not to reply to a comment or to postpone their posts for a few hours, either because they simply feel like procrastinating or they want to take the time to plan out how to present themselves to others (cf. Turkle 2011). Some of this sense of flexibility and agency over the tempo of social exchanges can, however, be diminished when communications are posited one-on-one and users feel themselves ethically obliged to respond to the messages of others.

\section{UNEXPECTED OBLIGATIONS}

Online fora, and the health apps that link up to them, are intentional communities. But health apps, with their arrays of settings and user notifications, can also engage users in unintentional, private (i.e. one-on-one) exchanges. In our encounters with various facets of these technologies, the features that surprised us the most were the unexpected relations of care that could be created through apps that initially appeared to be personal trackers but in actual fact, share data and enable communication between users. When we first tried out mood and emotion trackers, it was clear that they kept logs, charts and diagrams of our health data. But what we did not realise was that unless we changed the settings, many of them automatically shared our information with other users. Most importantly, those other users could - and did - message us in response to our data. While the ostensible purpose of the message feature is to enable users to encourage or support, their effects can be anything but supportive, as explained by Merino Ortiz:

My first time trying out one of the mood tracking diaries, I opened the app and was directed to an electronic notepad where I could write a post about my mood using a few characters. It was not meant to be a whole diary entry, just a snapshot of my mood at the time. I 
wrote down something about how unhappy I was feeling, and almost instantly I had a message from another user expressing sympathy for me. And then another one! New messages kept arriving throughout the evening. Some of them came at unexpected times, for example when I was sitting down to dinner with my family. I was actually feeling quite good by then, and my earlier emotions were the last thing I wanted to be thinking about.

Unaware that the information would be automatically communicated to other users, we had not anticipated such encounters. What interests us about this exchange is how ordinary health app users might, like us, at first think they are engaging with a simple tracking device and end up inadvertently being drawn into relations of care with the complete strangers who respond to their posts. What are their ethical responsibilities to those who contact them?

Talking over our experiences with using health apps with others, we discovered that the 'ordinary' or 'everyday' ethics of their use often involved both intentional and unexpected forms of interaction; in other words, we were not alone in being surprised by unexpected requests for communication. The most thought-provoking narrative came from a student in her early twenties who uses a similar emotion tracker and recounted how challenging she found it when someone she did not know began to message her about their emotional and psychological struggles:

I was having a bad day and wrote something [into the app] along the lines of 'I'm feeling angry, why won't people do things the way I want them to?' Almost immediately I had three replies from other users, ranging from 'we cannot control other people's actions, acceptance is key' to 'I know what you mean - my parents annoy me so much when they do things their way!' I replied to the last message and after a few exchanges, my correspondent began writing more and more about her parents. She informed me that they were both alcoholics and that she was really struggling, at times wondering what was the point of it all. I became genuinely concerned. How old was she? And why did I get the distinct impression 'she' was a 'she'? Her username was rather non-descript. I found myself suggesting she look into ALANON [a Twelve Step programme for family members of addicts and alcoholics], as leaving her alone in such despair felt like neglect.

The next morning I'd almost forgotten about the whole thing when I suddenly got another message from my 'new friend'. She wanted to 
know how I was doing, and if I felt better. She also wanted to let me know she had been looking into ALANON and might be going to a meeting near her. I looked at my phone and a huge sense of regret filled me. Did I really want to establish constant communication with this person? But then again, what was the point of reaching out to others if I had no intention of holding more than one conversation with them? In the end, I didn't reply, as it felt inappropriate to carry on.

My 'friend', however, carried on messaging me, asking me how I was feeling, and expressing concern over my silence. I found this even more bizarre. How come she seemed to care so much and I so little? After about a week she stopped messaging me. A month later I deleted the app out of sheer exasperation: I didn't want to be constantly reminded of the guilt I felt for not replying. But deleting the app, didn't delete my guilt, as it only severed the possibility of making amends or ever communicating with her again.

This encounter raises profound questions about our ethical obligations to strangers as they attempt to build intimacy with us. In this case, the narrator of this account felt at first obligated to respond with advice, but later felt unable to assist in the way that seemed to be desired, leaving her in an ethical conundrum that never quite went away, even after the app was deleted. But it also leaves us wondering, at what point do we feel obligated to respond to others? And how much of a sustained engagement is enough, when the burden begins to feel too heavy to carry? How might imagining the characteristics of one's interlocutor - in this case the narrator had the distinct impression she was conversing with a young girl, which added to the sense of protectiveness she felt towards her - both shape our sense of what is ethical and shift our ability to act on our perceived ethical obligations? Would the user's initial need to 'reach out' have been different if she perceived the person messaging her to be an older man? Does it matter who that person may or may not be? Clearly, she felt a need to distance herself from the person who was messaging her, but on the other hand, felt some responsibility for her/his welfare. The common use of the moniker of 'friend', particularly among young people, for anyone from a long-time friend or relative who is a part of our Facebook network to a complete stranger who messages us out of the blue, further complicated her ability to distinguish where the boundaries of her obligations might lie. 


\section{CONCLUSION}

In her study of young Americans' use of Facebook and other social media to end romantic relationships, Ilana Gershon (2010) argues that in our efforts to determine the appropriate ways to use (and not use) the array of forms of communication available to us, we engage in collectively constituting new 'idioms of practice' to guide our decision-making. This activity is, however, fraught, as not only technologies, but our uses of them, are continually changing.

Our aim here has been to focus on the personal, embodied, social and ethical dimensions of new forms of practice with health apps, examining how these technologies extend enactments of care for the self and for others by enabling potentially never-ending, real-time inter-activity. Health apps can translate our personal information into messages that mould our bodily behaviours or calendars that predict our future health and states of mind. They can also transform strangers into 'friends', with both positive and negative consequences.

Our experiences of trying out various health apps suggest they can lead to unexpected relations and demands, constituting a sense of obligation to oneself as well as to other users. Whether trying to meditate 'better' in order to improve one's statistics, or feeling fraudulent in wanting 'connection' but being unable to alleviate the suffering of name-less, face-less 'friends', some of these interactions will haunt us long after we have hit the 'delete' button. We have thus argued that in contrast to Bauman's (2003) depiction of digital technologies as creating virtual communities in which one can choose to log off in an instant, some of the instantaneous communication you receive can sometimes draw you into circumstances that require a moral obligation to act. Virtual communities are not necessarily fleeting, 'liquid' relations which one can dip into and then exit out of without any repercussions. In fact, they can enable long-term, sustained engagements, while also catering to more short-lived encounters. Nor are they solely tools for augmenting self-responsibility. Rather, the drive to self-manage often comes in tandem with the creation of new relations and ethical responsibilities for others (cf. Trnka and Trundle 2014).

We have offered a snapshot of our experiences with a handful of health apps in the hope of opening up conversation about the many pressing ethical issues these new technologies raise. As Imar De Vries has said of mobile wireless media more generally, because of 'their ruthless and pervasive connectivity' $(2012,126)$, these technologies have the ability to profoundly transform how we relate to ourselves and to others. We are aware that we have raised many more questions than we have answered; our intention here, however, has not 
been to provide a blueprint for how we should relate to - and through - these new technologies, but to underscore how they require a framing of ethical questions beyond those concerning how commercially-salient data is collected by health app creators. Recasting how information is shared as well as the temporal possibilities of social exchanges, health apps enable 'friends' we know or are coming to know, as well as those we do not want to know, to enter into some of the most intimate aspects of our lives, as they unfold in the open-ended flow of time. In doing so, health apps demand a rethinking of the ethics of how we constitute and care for both the self and a variety of known and unknown others.

\section{ACKNOWLEDGEMENTS}

Funding for this project was received from the University of Auckland's Summer Scholar's programme.

\section{NOTES}

1 Susanna Trnka is an Associate Professor at the University of Auckland. Her research specialties include the body and technology, medical anthropology, citizenship and subjectivity.

Email: s.trnka@auckland.ac.nz

2 Andrea Merino Ortiz is currently completing her Masters in Anthropology at the University of Auckland. In 2016, she completed a Summer Research Scholar programme for Dr Susanna Trnka.

Email: amero52@aucklanduni.ac.nz

3 Quotes have been altered in order to conceal the identities of both the posters and the specific online fora.

\section{REFERENCES}

Adams, Vincanne, Michelle Murphy, and Adele Clarke. 2009. 'Anticipation: Technoscience, Life, Affect Temporality'. Subjectivity 28:246-65.

Bardzell, Shaowen, and Jeffrey Bardzell. 2006. 'Sex-Interface-Aesthetics: The Docile Avatars and Embodied Pixels of Second Life BDsM'. Accessed March 24, 2016 from http://www.ics.uci.edu/ johannab/sexual.interactions.2006/ papers/ShaowenBardzell\%26JeffreyBardzell-SexualInteractions20o6.pdf. 
Bauman, Zygmunt. 2003. Liquid Love: On the Frailty of Human Bonds. Malden, MA: Polity.

Boellstorff, Tom. 2015. Coming of Age in Second Life: An Anthropologist Explores the Virtually Human. Princeton, NJ: Princeton University Press.

Brotsky, Sarah R. and David Giles. 2007. 'Inside the "Pro-ana" Community: A Covert Online Participant Observation'. Eating Disorders 15 (2): 93-109.

Brodwin, Paul. 2013. Everyday Ethics: Voices from the Front Line of Community Psychiatry. Berkeley: University of California Press.

Broom, Alex. 2005. 'Virtually He@lthy: The Impact of Internet Use on Disease Experience and the Doctor-patient Relationship'. Qualitative Health Research $15: 325-45$.

Buijink, Arthur, Benjamin Jelle Visser, and Louise Marshall. 2013. 'Medical Apps for Smartphones: Lack of Evidence Undermines Quality and Safety'. Evidence-Based Medicine 18 (3): 90-92.

De Vries, Imar. 2012. Tantalisingly Close: An Archaeology of Communication Desires in Discourses of Mobile Wireless Media. Amsterdam: Amsterdam University Press.

Downey, Gary Lee and Joseph Dumit, eds. 1997. Cyborgs \& Citadel: Anthropological Interventions in Emerging Sciences and Technologies. Santa Fe, NM: School of American Research Press.

Dumit, Joseph. 2012. Drugs for Life: How Pharmaceutical Companies Define Our Health. Durham, NC: Duke University Press.

Fassin, Didier. 2012. 'Introduction: Toward a Critical Moral Anthropology'. In $A$ Companion to Moral Anthropology, edited by Didier Fassin, 1-18. Malden, MA: Wiley-Blackwell.

Foucault, Michel. 1997[1994]. Ethics: Subjectivity and Truth. New York: The New Press.

George, Molly, Fitzgerald, Ruth P. and Chrystal Jaye. 2016. 'Peripheral Cosmopolitans, An Introduction'. Sites: A Journal of Social Anthropology and Cultural Studies 13 (1):1-12. 
Gershon, Ilana. 2010. The Break Up 2.o: Disconnecting over New Media. Ithaca \& London: Cornell University Press.

Giddens, Anthony. 1991. Modernity and Self-identity: Self and Society in the Late Modern Age. Palo Alto: Stanford University Press.

Lambek, Michael. 2010. Ordinary Ethics: Anthropology, Language, and Action. New York: Fordham University Press.

Lewis, Tania. 2006. 'DIY Selves? Reflexivity and Habitus in Young People's Use of the Internet for Health Information'. European Journal of Cultural Studies $9(4): 461-79$.

Lupton, Deborah. 2012. 'M-health and Health Promotion: The Digital Cyborg and Surveillance Society'. Social Theory and Health 10 (3): 229-44.

- 2013. 'Quantifying the Body: Monitoring and Measuring Health in the Age of mHealth Technologies'. Critical Public Health 23 (4):393-403.

- 2014a. 'The Commodification of Patient Opinion: The Digital Patient Experience Economy in the Age of Big Data' Sociology of Health \& Illness $36(6): 856-69$.

- 2014b. 'Critical Perspectives on Digital Health Technologies'. Sociology Compass 8 (12): 1344-59.

Preece, Jennifer J. 1999. 'Empathy Online’. Virtual Reality 4: 74-84.

Riaz, Saleha. 2015. 'Health Apps on the Rise but Barriers Remain, Reveals Study'. Mobile World Live. Accessed 3 February 2016 from http://www.mobileworldlive.com/apps/news-apps/health-apps-on-the-rise-but-barriers-remainreveals-study/.

Rose, Nikolas. 1990. Governing the Soul: The Shaping of the Private Self. New York: Routledge.

- 2006. The Politics of Life Itself: Biomedicine, Power, and Subjectivity in the Twenty-first Century. Princeton, NJ: Princeton University Press.

Tanner, Claire, Maher, Janemaree, and Suzanne Fraser 2013. Vanity: 21st Century Selves. London: Palgrave Macmillan. 
Trnka, Susanna. 2016. 'Digital Care: Agency and Temporality in Young People's Use of Health Apps'. Engaging Science, Technology, and Society 2:248-65.

- 2017. One Blue Child: Asthma, Responsibility, and the Politics of Global Health. Palo Alto: Stanford University Press.

Trnka, Susanna, and Catherine Trundle. 2014. 'Competing Responsibilities: Moving Beyond Neoliberal Responsibilisation'. Anthropological Forum: A Journal of Social Anthropology and Comparative Sociology 24 (2):136-153.

Turkle, Sherry. 2008. 'Always-on/Always-on-you: The Tethered Self'. In Handbook of Mobile Communication and Social Change, edited by James E. Katz, 121-138. Cambridge, MA: MIT Press.

- 2011. Alone Together: Why We Expect from Technology and Less from Each Other. New York: Basic Books.

Wynn, Lisa, Angel Foster and James Trussell. 2010. “Would You Say You Had Unprotected Sex If...?" Sexual Health Language in Emails to a Reproductive Health Website' Culture, Health and Sexuality 12 (5):499-514. 